\title{
POLÍTICA DE ASSISTÊNCIA SOCIAL NO BRASIL E PROGRAMA BOLSA FAMÍLIA: APONTAMENTOS CRÍTICOS
}

\author{
ASSISTANCE SOCIAL POLICY IN BRAZIL AND BOLSA FAMÍLIA \\ PROGRAM: CRITICAL POINTS
}

Haidée de Caez Pedroso Rodrigues

\section{TRABAJO SOCIAL GLOBAL 2015, 5 (8), 3-25}

\begin{abstract}
Resumo
O presente artigo versa sobre a política de assistência social no Brasil. Tem como fundamento a teoria social crítica e traz como ponto de partida reflexões sobre a relação entre acumulação do capital e o surgimento da questão social. Considerando a formação social brasileira e a correlação de forças entre as classes sociais, buscamos apresentar historicamente como se constituíram os direitos sociais no país. No debate contemporâneo são analisadas as principais determinações sociais, políticas e econômicas que mediaram a implementação das políticas sociais na conjuntura de reformas neoliberais na década de 1990, quando passam a se destacar os programas de transferência de renda enquanto estratégias de combate à pobreza. Com o ingresso do Partido dos Trabalhadores à frente do governo federal, algumas mudanças ocorreram principalmente no âmbito da gestão da política de assistência social, mas ainda observamos permanecer o caráter liberalconservador das políticas sociais, e em especial, às ações preconizadas no Programa Bolsa Família. Tais elementos apontam desafios para os dos profissionais que atuam na gestão e execução dessas políticas sociais que estão comprometidos com os interesses da classe trabalhadora, tanto no que se refere à sua formação quanto ao seu exercício profissional.
\end{abstract}

\begin{abstract}
This article deals with the social assistance policy in Brazil. It Is based on the critical social theory and brings as a starting point reflections on the relationship between capital accumulation and the emergence of the social question. Considering the Brazilian society and the correlation of forces between social classes, we try to present as the social rights were made in the country. Into contemporary debate, we have reviewed the main social causes, political and economic that mediated the implementation of social policies in the context of neoliberal reforms in the 1990s, when come to the fore the income transfer programs as poverty reduction strategies. When the Trabalhadores Party takes the federal government, some changes occurred mainly in the management of social welfare
\end{abstract}

Identificador permanente de este artículo: http://hdl.handle.net/10481/36788

Recibido: 20-04-2015 Revisado: 09-06-2015 Aceptado: 20-06-2015 Publicado: 25-06-2015 
policy, but the liberal-conservative character of social policies remains, and in particular the actions recommended in the Bolsa Familia Program. These elements point to the challenges of professionals working in the management and implementation of these social policies that are committed to the interests of the working class, both in terms of their training with regard to their professional practice.

PC.- superpopulação relativa, política social, assistência social, programa bolsa família.

$K W$.- overpopulation relative, social policy, social welfare, bolsa família program.

\section{Introdução}

Temos observado na literatura brasileira, e em especial no Serviço Social, um conjunto de reflexões acerca dos atuais desdobramentos da política de assistência social e dos programas de transferência de renda enquanto estratégias de combate à pobreza. Embora se enfatize o Programa Bolsa Família enquanto o "carro-chefe" da intervenção do governo no combate à pobreza no Brasil, este é caudatário de um conjunto de mudanças que passam a vigorar no país após o final dos anos de 1980, tanto no âmbito da política quanto da economia, após a crise mundial e a correlação de forças entre as classes sociais.

Portanto, para analisar a política de assistência social e os programas de transferência de renda partiremos dos pressupostos teórico-metodológicos fundamentados na teoria social crítica no sentido apreender o objeto na sua totalidade, ou seja, considerando o conjunto de determinações históricas, políticas, econômicas e sociais que envolvem o surgimento e desenvolvimento da política de assistência social brasileira.

O objetivo desse artigo é o de refletir acerca da consolidação da política de assistência social no Brasil e os desdobramentos políticos e econômicos dos programas de transferência de renda para apontar os principais dilemas e desafios postos ao Serviço Social na contemporaneidade.

Nosso artigo está dividido em três partes. A primeira delas tenta esboçar, de forma sucinta, um panorama das particularidades históricas da constituição das políticas sociais no Brasil. No segundo momento, traçaremos as principais críticas que vem sendo atribuídas à concepção e à implementação do Programa Bolsa Família. E para finalizar, apontaremos algumas reflexões para a formação e exercício dos assistentes sociais. 


\section{Política de Assistência Social no Brasil: uma breve aproximação a partir de suas particularidades históricas}

\subsection{Acumulação do capital e questão social}

Embora os dados oficiais informem a redução da pobreza no Brasil ${ }^{1}$, sabemos que o fenômeno do pauperismo esteve presente desde os primórdios do desenvolvimento do capitalismo e que seu aumento ou retrocesso dependem de um conjunto de medidas econômicas, políticas e sociais na órbita do Estado a depender tanto de conjunturas históricas quanto da correlação de forças entre as classes sociais. A política de assistência social no Brasil, e em diferentes países, surge para atender as necessidades do segmento de trabalhadores pauperizados.

No entanto, o pauperismo é produto da dinâmica inerente do capital. Desde que o capitalismo se consolidou enquanto modo de produção, através da revolução industrial, da divisão social e técnica do trabalho e da generalização do trabalho assalariado, que a expansão das riquezas veio acompanhada pelo desemprego de uma parcela considerável dos trabalhadores.

Assim, a própria consolidação desta sociedade gerou mecanismos que expulsam os trabalhadores das fábricas criando o que Marx (1998) denominou de superpopulação relativa e/ou exército industrial de reserva. Esse contingente de desempregados representa um estoque de trabalhadores sempre disponíveis para as demandas do capital. No interior desse reservatório de força de trabalho se desenvolvem mecanismos que empurram os salários dos empregados para baixo, pressionam para que eles trabalhem com mais intensidade e por mais tempo, criam uma grande massa humana pronta a ser convocada quando assim desejar o capital e condenam uma parte da classe trabalhadora à ociosidade forçada.

Portanto, o desemprego na sociedade capitalista deve ser entendido não como produto exterior ou mero distúrbio involuntário do sistema de produção, mas antes, como produto histórico necessário da acumulação ou do desenvolvimento da riqueza no sistema capitalista. 
Historicamente, segmentos da classe trabalhadora que tanto estavam inseridos nos processos produtivos e/ou vivenciavam situações de pobreza devido ao processo de urbanização e industrialização, passaram a reivindicar por melhores condições de trabalho e de vida. É quando podemos afirmar tratar-se do surgimento da questão social².

Portanto, partindo do princípio de que há uma relação umbilical entre as dimensões da política e da economia, consideraremos que as políticas sociais emergem e só podem ser compreendidas historicamente a partir da intervenção do Estado na questão social. No entanto, elas não se desenvolveram de forma homogênea, assumiram traços particulares a depender de cada país/região, uma vez que dependem também da capacidade de organização e pressão da classe trabalhadora, do grau de desenvolvimento das forças produtivas e das correlações e composições de força no âmbito do Estado (Behring; Boschetti, 2011).

\subsection{Particularidades históricas da política social brasileira}

Autores de relevância intelectual no Brasil (Carvalho, 2011; Behring \& Boschetti, 2011; Couto et. al., 2010) desenvolvem reflexões acerca da consolidação dos direitos sociais no país. Destacaremos alguns elementos que expressam nossa formação sócio histórica e que influenciaram no desenvolvimento da legislação social.

O Brasil não vivenciou um modelo "clássico" de revolução burguesa, mas sim contou com o processo chamado por Mazzeo (1997) de "via prussiano-colonial". Esse processo tratou, na verdade, da institucionalidade do Estado nacional sem a participação das massas populares, com o exclusivo domínio da elite agrária, com uma matriz teórico-ideológica liberal de caráter conservador e reacionário. A transição para uma sociedade moderna se fez mudando a sua institucionalidade na aparência jurídica, mas mantendo os laços com o passado em termos de organização e práticas econômicas, políticas e culturais.

Tal contexto histórico fez com que ainda hoje esteja presente o forte interesse da burguesia agrária, mas também de um forte movimento popular junto ao campo além dos movimentos sociais urbanos.

Decorrente deste processo, outro aspecto a ser considerado é o peso do escravismo que influenciou as relações entre as classes, formando historicamente, de forma deletéria para 
os trabalhadores, um caldo cultural baseado no trato pessoal de questões de ordem pública e o forte clientelismo e patrimonialismo na gestão do Estado (Mazzeo, 1997; Behring, Boschetti, 2011).

Tais características vão marcar a relação entre o Estado e os trabalhadores. Ainda assim, temos que destacar que desde a proclamação da república em 1889 até 1930 algumas medidas de proteção social foram implementadas devido a pressões populares e internacionais: em 1891 foi regulado o trabalho de menores na capital federal, culminando na aprovação do Código de Menores em 1917; a garantia do direito de sindicalização a algumas categorias de trabalhadores, principalmente com o maior reconhecimento dos sindicatos na área rural que trabalhavam com café e por conta da mobilização dos trabalhadores imigrantes; a aprovação da Lei Eloy Chaves, que criou a obrigatoriedade de criação de Caixas de Aposentadorias e Pensões (CAPs) para algumas categorias estratégicas de trabalhadores como ferroviários e marítimos (Behring, Boschetti, 2011).

A década de 1920 tratou-se de um período de forte efervescência política, com a criação em 1922 do Partido Comunista Brasileiro e com a realização neste mesmo ano da Semana de Arte Moderna. No âmbito da economia ocorreu a grave crise econômica mundial de 1929 , fazendo com que houvesse um rearranjo político entre frações da burguesia no país (Carvalho, 2011).

A partir de 1930 contamos com um intenso investimento do Estado na industrialização do Brasil quando Getúlio Vargas assume a presidência. É quando podemos afirmar que se trata do surgimento da questão social no Brasil a partir do protagonismo da classe trabalhadora no cenário político, demandando do Estado e da burguesia um conjunto de respostas às mazelas sociais oriundas da acumulação de capital que estava se instituindo.

Portanto, de 1930 a 1964, foram implementadas uma série de medidas sociais. É quando se institui, de forma ampliada, as Caixas e os Institutos de Aposentadorias e Pensões, CAPs e IAPS, que se organizavam por ramo de categoria e asseguravam como benefícios o direito à aposentadoria e pensão, o acesso ao socorro médico e a compra de medicamentos a preços reduzidos, e eram mantidos através da contribuição de empregados e empregadores, sem contar com a participação do Estado (Couto, 2006).

Mas tais medidas se destinavam somente aos trabalhadores vinculados ao setor formal e que contribuíam para essas instituições. A consequência disto é que um número significativo 
de trabalhadores, tanto urbanos quanto rurais, ficou à margem desse sistema, pois se situavam na informalidade, dependendo de assistência filantrópica. Em 1942 criou-se a Legião Brasileira da Assistência (LBA) que inicialmente tinha como propósito atender as famílias dos soldados que haviam se alistado na guerra, mas que passa também a assistir aqueles trabalhadores que não estavam vinculados ao emprego formal. Tratava-se de ações voluntárias, sem caráter técnico e/ou programático.

Os anos entre 1930 e 1945 foram importantes para a ampliação da legislação trabalhista, ainda que somente para os trabalhadores formais. Mas foi nesse período que: estabeleceuse a jornada de trabalho de oito horas para comércio e indústria; regulamentou-se o trabalho feminino; foi criada a carteira de trabalho; criação de comissões e juntas de trabalho (início da justiça do trabalho); direito de férias; criação do salário mínimo e da Consolidação das Leis Trabalhistas (CLT) (Carvalho, 2011).

Esse quadro histórico vai contar com mudanças ao longo dos governos, mas ainda carregando o forte apelo populista, com medidas voltadas à industrialização do país e com a abertura ao capital internacional a partir dos anos de 1950-1960. No entanto, a partir de 1960 assume João Goulart como presidente e avança nas chamadas reformas de base: agrária, fiscal, bancária e educacional, buscando atender aos anseios das mobilizações do campo e da cidade.

O golpe militar de 1964, de certa forma, foi uma ação política que buscou conter as reformas que estavam em curso, pois poderia levar ao "perigo comunista". O cerceamento dos direitos civis e políticos perduraram até a abertura democrática nos anos de 1980. Mas algumas medidas sociais foram adotadas nesse período, inclusive, para amenizar as contradições da ditadura. Em 1971 foi criado o Fundo de Assistência Rural (Funrural) que efetivamente incluía os trabalhadores rurais na previdência, mas seus recursos vinham de um imposto sobre produtos rurais, pago pelos consumidores, e de um imposto sobre as folhas de pagamentos das empresas urbanas, não onerando a burguesia agrária (Carvalho, 2011).

Em 1966 foi criado o Instituto Nacional de Previdência Social (INPS) que acabava com os CAPs e IAPs e unificava o sistema e centralizando sua gestão no poder público federal, com exceção do funcionalismo público, civil e militar. O governo acabou com a estabilidade no emprego, e para compensar, criou o Fundo de Garantia por Tempo de Serviço (FGTS) em 1966, que era pago pelos empresários e que tinha a função de seguro-desemprego. Criou- 
se o Banco Nacional da Habitação (BNH) cuja finalidade era facilitar a compra da casa própria aos trabalhadores de baixa renda.

Portanto, até os anos de 1970, os trabalhadores situados à margem dos sistemas de proteção social tinham que acessar aos serviços beneficentes das políticas de assistência e saúde nas denominadas santas casas de misericórdia, que se caracterizavam pela filantropia e benemerência, sem assumir a condição de política pública. Enquanto que os trabalhadores formais acessavam as políticas sociais a partir do INPS. O governo somente investia em campanhas de vacinação em massa, mas ainda de forma bastante residual. Portanto, estabelecendo uma forte cisão entre os trabalhadores inseridos de forma formal na economia e aqueles situados na informalidade.

Os movimentos de oposição fizeram-se presente durante todo o período da ditadura militar, principalmente nos anos de 1980, com a forte atuação sindicatos, organizações civis e religiosas, movimentos sociais urbanos, associações de profissionais de classe média, artistas e intelectuais. Momento que contou com a criação do Partido dos Trabalhadores e de intensa mobilização sindical com os operários dos setores que haviam se expandido na economia com o "milagre" econômico, ou seja, metalúrgicos das automobilísticas e da siderurgia da região metropolitana de São Paulo (Carvalho, 2011).

No processo de reabertura democrática esses movimentos contribuíram para a garantia de prerrogativas que atendessem aos interesses populares na Constituição Federal de 1988, chamada a "Constituição Cidadã". Tais mobilizações apresentaram pautas políticas que atendiam a diferentes segmentos da sociedade, mas principalmente, evidenciavam as contradições da acumulação do capital e do pauperismo. Devida a essa correlação de forças, ampliou-se a Seguridade Social brasileira que passa a ser composta pelas políticas de saúde, assistência e previdência social, elevando-as a patamar de direito social. A primeira delas, de caráter universal e gratuita, onde todos os cidadãos brasileiros tem acesso. A segunda é para aqueles cidadãos que dela necessitar. Ambas não possuem caráter contributivo, somente a previdência social que concede benefícios e aposentadorias aqueles que contribuem via imposto previdenciário. Portanto, buscando romper com a cisão histórica entre os trabalhadores formais e o resto da população.

As políticas não-contributivas - a assistência social e saúde - foram regulamentadas através da criação da Lei Orgânica da Assistência Social (LOAS) ${ }^{3}$ e da criação do Sistema Único de Saúde (SUS) ${ }^{4}$. Ambas as legislações inovaram quanto à participação popular, uma 
vez que preveem canais de controle social como as conferências municipais, estaduais e nacional, além dos referidos conselhos paritários entre sociedade civil e governo. No entanto, tais espaços vêm sendo utilizados para manobras políticas de caráter privado e são alvos de constantes embates políticos que expressam diferentes projetos societários.

Apesar desses avanços democráticos com a Constituição Federal, já estava em vigor nos países latino americanos medidas de cunho neoliberal ${ }^{5}$ como "saídas" para a crise econômica dos anos de 1970-1980. O final dos anos de 1980, mas, principalmente, os anos de 1990, caracterizaram-se por um período marcado por privatizações de serviços e empresas públicas, desregulamentações financeiras e intensas medidas voltadas à reestruturação produtiva.

\section{Neoliberalismo, programas de transferência de renda e assistência social}

Como prevê o pacote neoliberal, o Estado deve conter gastos sociais. Por tais razões, mesmo após a elaboração da Constituição Federal de 1988 o Estado não priorizou o investimento do fundo público na implementação das políticas sociais nela preconizada. Resultado disso foi, por um lado, a acumulação e concentração do capital dos grandes empresários e, por outro, a crescente pauperização da grande massa da população.

Mas o Estado não pôde deixar de dar respostas às expressões da questão social. Fará isso numa perspectiva focalizadora que trabalha com a lógica da fragmentação das políticas, visando atender resultados de curto alcance e os critérios de acesso estão baseados quantitativamente na renda, além de distinguir por mérito e não por direito àqueles que terão acesso e/ou continuidade no acesso aos benefícios sociais.

A política social focalizada de combate à pobreza nasce e se articula intimamente com as reformas liberais e tem por função compensar, de forma parcial e muito limitada, os estragos socioeconômicos promovidos pelo modelo liberal [...] trata-se de uma política social apoiada num conceito de pobreza restrito, que reduz o número real dos pobres, suas necessidades e o montante de recursos públicos a serem gastos. Ela procura adequar ao permanente ajuste fiscal a que se submetem os países periféricos, por exigência do FMl e do capital financeiro para garantir o pagamento das dívidas públicas [a juros exorbitantes...] (Filgueiras; Gonçalves, 2007, p. 155-156). 
São com essas características que serão implementadas na década de 1990 diferentes programas de caráter focalizado voltados ao combate à pobreza, como o Plano de Combate à Fome e à Miséria pela Vida (1993) e o Programa Comunidade Solidária (1995).

As políticas de saúde e previdência social também são impactadas pelas medidas neoliberais. O exemplo disto é o sucateamento dos serviços públicos de saúde devido ao baixo investimento público e a abertura para os planos privados. A área da previdência contará com uma série de medidas que ampliarão o tempo para a aposentadoria e de cálculos para a redução dos benefícios, além da ampliação de regras que favorecem os fundos privados de pensão, entre outras medidas. Fazendo com que se criasse agora uma cisão entre aqueles trabalhadores com condições de pagar por serviços privados (planos de saúde e previdência privados) e aqueles trabalhadores pobres que acessam às precarizadas políticas sociais (Mota 2005).

No projeto de continuidade ao aprofundamento das medidas neoliberais, temos a partir dos anos 2000 um conjunto de intervenções sociais voltadas à implementação de programas de renda mínima, como o Programa Nacional de Renda Mínima vinculada à educação - "Bolsa Escola"6 (2001), o Programa Nacional de Renda Mínima vinculado à saúde - "BolsaAlimentação"7 e o Auxílio-Gás ${ }^{8}$ (2001).

A partir do governo Lula, em 2003, ocorreram inflexões na área social cuja principal delas foi a implantação de um programa de renda mínima que se inicia com um processo de unificação dos programas nacionais de transferência de renda mencionados anteriormente, agora passando a se denominar "Bolsa Família". Segundo o portal do Ministério de Desenvolvimento Social e Combate à Fome (MDS) o Programa Bolsa Família (PBF) ${ }^{9}$ tem se constituído como:

O principal programa de transferência direta de renda com condicionalidades do governo federal. Sua estrutura está fundamentada em torno de três dimensões: promoção do alívio imediato da pobreza, reforço ao exercício de direitos sociais básicos na área da saúde e educação e articulação com programas complementares, voltados ao desenvolvimento das famílias, para que tenham condições de superar situações de vulnerabilidade e pobreza. Entre os exemplos de programas complementares ao PBF incluem-se programas de geração de trabalho e renda, combate ao trabalho escravo, alfabetização de jovens e adultos e acesso à energia elétrica (MDS, 2008, p. 24). 
Atualmente o PBF situa-se no âmbito da política de assistência social, por consistir em benefício de caráter não contributivo, vinculado ao Ministério de Desenvolvimento Social e Combate à Fome (MDS). Com a inauguração do Sistema Único da Assistência Social SUAS, o programa integra a rede de atenção básica ${ }^{10}$ da política de assistência social.

As famílias que pretendem participar do programa são cadastradas nas secretarias municipais de assistência social, sendo incluídas no Cadúnico - Cadastro Único para Programas Sociais do Governo Federal - que se trata de um instrumento de coleta de dados que tem como objetivo identificar todas as famílias em situação de pobreza existentes no país. No entanto, após o cadastro e, mesmo a família estando dentro dos critérios estabelecidos pelo PBF, não significa que a mesma será incluída no programa. Isso dependerá da disponibilidade de vagas para cada município, em função de uma estimativa de famílias pobres, com base em estudo realizado com o apoio do IPEA (Instituto de Pesquisas Aplicadas) e da pesquisa do PNAD/2004 (Pesquisa Nacional por Amostra de Domicílios), além da provisão de recursos do orçamento público previstos para a execução do programa.

Quanto aos benefícios, eles podem ser ${ }^{11}$ : (1) Benefício Básico no valor de $\mathrm{R} \$ 77$ concedido apenas a famílias extremamente pobres (renda mensal por pessoa menor de até $R \$ 77$ ); (2) Benefício Variável no valor de $\mathrm{R} \$ 35$ concedido às famílias com crianças ou adolescentes de 0 a 15 anos de idade; (3) Benefício Variável à Gestante no valor de $R \$ 35$ concedido às famílias que tenham gestantes em sua composição, com pagamento de nove parcelas consecutivas, a contar da data do início do pagamento do benefício, desde que a gestação tenha sido identificada até o nono mês; (4) Benefício Variável Nutriz no valor de $\mathrm{R} \$ 35$ concedido às famílias que tenham crianças com idade entre 0 e 6 meses em sua composição, com pagamento de seis parcelas mensais consecutivas ${ }^{12}$; (5) Benefício Variável Vinculado ao Adolescente no valor de $R \$ 42$ concedido a famílias que tenham adolescentes entre 16 e 17 anos $^{13}$; (6) Benefício para Superação da Extrema Pobreza que é calculado caso a caso e que é transferido às famílias do PBF que continuem em situação de extrema pobreza (renda mensal por pessoa de até $\mathrm{R} \$ 77$ ), mesmo após o recebimento dos outros benefícios.

O PBF prevê as seguintes condicionalidades ${ }^{14}$ : na área de saúde, as famílias beneficiárias assumem o compromisso de acompanhar o cartão de vacinação e o crescimento e desenvolvimento das crianças menores de 07 anos. As mulheres na faixa de 14 a 44 anos também devem fazer o acompanhamento e, se gestantes ou nutrizes (lactantes), devem 
realizar o pré-natal e o acompanhamento da sua saúde e do bebê. Na educação, todas as crianças e adolescentes entre 06 e 15 anos devem estar devidamente matriculados e com frequência escolar mensal mínima de $85 \%$ da carga horária. Já os estudantes entre 16 e 17 anos devem ter frequência de, no mínimo, $75 \%$.

Também está previsto que as famílias que necessitem de acompanhamento social, este será feito por profissionais técnicos nos Centros de Referência de Assistência Social (Cras) e/ou Centros de Referência Especializada de Assistência Social (Creas), de acordo com as situações de vulnerabilidade e risco identificadas. Além de terem direito, em determinadas situações, a participarem das ações socioassistenciais.

Os Cras e Creas fazem parte do novo ordenamento jurídico-administrativo da política de assistência social iniciado em 2005 com a criação do Sistema Único da Assistência Social $\left(S U A S^{15}\right)$ que tem por objetivo constituir um sistema público que organiza os serviços socioassistenciais no Brasil. Estabelece que em cada centro de referência deva contar com, no mínimo, 01 profissional Assistente Social dentre os profissionais da equipe.

Existindo dois tipos de proteção social ${ }^{16}$. O primeiro é a Proteção Social Básica, destinada à prevenção de riscos sociais e pessoais, por meio da oferta de programas, projetos, serviços e benefícios a indivíduos e famílias em situação de vulnerabilidade social com ações nos Cras. A segunda é a Proteção Social Especial, destinada a famílias e indivíduos que já se encontram em situação de risco e que tiveram seus direitos violados por ocorrência de abandono, maus-tratos, abuso sexual, uso de drogas, entre outros aspectos com ações nos Creas.

Com a criação do SUAS, observa-se que muito se avançou em termos de gestão administrativa e a construção de uma nova institucionalidade para política de assistência social no Brasil, ampliando os seus objetivos e estabelecendo uniformidade e unidade na prestação dos serviços. No entanto, como se insere no contexto das reformas neoliberais, alguns desafios precisam ser sinalizados conforme apontam os estudos de Couto et. al. (2010).

O primeiro elemento refere-se à necessidade de integração e articulação com as demais políticas sociais para o atendimento às reais necessidades da população. Outra questão é que a execução e a priorização da política de assistência social dependem de pactuações entre os gestores das esferas municipal, estadual e federal, colocando na ordem do dia um 
conjunto de interesses políticos que muitas vezes impedem a plena execução do SUAS ${ }^{17}$. A fragilidade do controle social de forma efetiva como preconiza a legislação também se constitui em outro desafio, que se deve tanto à dificuldade de mobilização dos usuários desses serviços, quanto às manobras políticas que são realizadas para tomada de decisões. Em relação ao atendimento às demandas da população, este ainda se apresenta de forma rotineira e existem dificuldades na proposição e ampliação desses atendimentos. Um último elemento que pode ser aqui destacado refere-se ao "primeiro-damismo" quando ainda se faz presente o caráter patrimonialista da política social, principalmente nos municípios de pequeno porte, em que esposas de governantes dirigem a condução da política de assistência social, assumindo-a com forte cariz filantrópico e de benemerência, reproduzindo a lógica histórica de constituição da assistência no Brasil, o que dificulta a criação de uma cultura pública dos direitos sociais.

No entanto, a constituição da Seguridade Social brasileira avançou no sentido da ampliação dos direitos sociais, se comparada ao seu histórico. Mas a sua implementação efetiva ainda é alvo de lutas e embates políticos e, portanto, é um projeto que ainda está em disputa.

Os programas e projetos de enfrentamento à pobreza, que estão sob a execução da política de assistência social, são alvo de constantes embates teórico-políticos no cenário contemporâneo. Coexistindo diferentes concepções de pobreza e de enfrentamento da mesma, bem como a forma como esses programas impactam na reprodução econômica e ideológica da população.

Nesse universo plural e democrático, nossa análise teórica e ídeo-política considera que o atual Programa Bolsa Família compõe um conjunto de ações já em curso que buscam aprofundar as medidas neoliberais, mas que agora assumem novas particularidades. Vejamos, então, as principais críticas ao Programa Bolsa Família (PBF) nesse sentido.

\section{Programa Bolsa Família: apontamentos críticos}

No período de dez anos de existência o PBF já atingiu 13,8 milhões de famílias o que significa quase 50 milhões de pessoas, o que corresponde a cerca de $1 / 4$ da população brasileira. Conta com investimento anual em torno de $\mathrm{R} \$ 24$ bilhões, que pode ser considerado investimento baixo se comparado ao total de orçamento da união, pois 
equivalente a somente $0,46 \%$ da economia nacional ${ }^{18}$. Portanto, aparentemente, um programa com custo-benefício bastante favorável para a gestão do Estado.

Além disto, um dos argumentos mais recorrentes dos defensores do PBF refere-se ao seu caráter altamente redistributivo que promove a redução da desigualdade no país (Constanzi; Fagundes, 2010). No entanto, os dados mostram o contrário. Segundo a Pesquisa Nacional por Amostra de Domicílios (PNAD) de 2013, o chamado Índice Gini, que varia de 0 a 1, piorou de 0,496 em 2012 para 0,498 em $2013^{19}$. A respeito da renda média dos brasileiros, essa tem aumentado em $5,7 \%$, passando para $R \$ 1.681$ por trabalhador, mas a média aumentou mais no topo da pirâmide $(6,4 \%)$ do que na base $(3,5 \%)$, não contribuindo para diminuir a desigualdade. Portanto, a forte desigualdade no país ainda continua presente uma vez que o contingente de $1 \%$ dos brasileiros mais ricos ainda ganha quase cem vezes mais que os $10 \%$ mais pobres. E que a renda média é de $\mathrm{R} \$ 235$ por mês entre os 8,6 milhões de trabalhadores mais pobres, contra $R \$ 20.312$ entre os 864 mil no topo da pirâmide.

Mas, se comparados aos programas implementados no Brasil nos anos de 1990, podemos perceber que um dos avanços com o PBF foi o aumento do benefício pago às famílias apesar de contar com valores muito baixos se comparado com o valor do salário mínimo ${ }^{20}$ além da capacidade de incorporação de um maior número de beneficiários que os programas anteriores. Isso revela que o PBF obteve impactos significativos sobre a reprodução física das famílias beneficiadas, possibilitando maior acesso ao consumo de alimentos essenciais e contribuindo para a movimentação da economia principalmente dos pequenos municípios. Em que pese esses aspectos "positivos" muitas famílias necessitam complementar sua renda e isso ocorre, na maioria dos casos, via trabalho informal e/ou precarizado. E ainda existem famílias em situação de pobreza absoluta que não conseguiram acessar ao programa.

A Cartilha do PBF indica como "portas de saída": alfabetização, capacitação profissional, apoio à agricultura familiar, geração de ocupação e renda e microcrédito, acesso a serviços de saúde e educação (Silva; Yasbeck; Giovanni, 2008, p. 139). No entanto:

As únicas possibilidades de geração de renda que conseguem ter acesso, nesse contexto, são por meio da realização de faxinas esporádicas, da cata de latinhas e da confecção de artesanatos. Muitas dessas atividades tiveram início a partir da participação, como beneficiárias do Bolsa Família, em cursos disponibilizados 
por instituições governamentais e não-governamentais envolvidas com execução do programa. (Rodrigues, 2008, p. 234).

Podemos observar, então, que o PBF preconiza que as alternativas para superação da pobreza estão centradas no indivíduo e na sua inserção em diferentes políticas, programas e projetos. Portanto, a sua saída da pobreza vai depender da aquisição, ou não, de novas capacidades individuais. Não entra aqui em questão as determinações econômicas, políticas e sociais que fundam as relações desiguais sob o modo de produção capitalista.

Portanto, o PBF expressa o caráter liberal-conservador já proposto para as reformas neoliberais das políticas sociais desde os anos de 1990, não rompendo com suas bases fundamentais. Tal perspectiva, de matriz teórica positivista, centra seus estudos nas categorias como "capital humano", "empoderamento", "capacidades", entre outras, e não se propõe a uma análise crítica mediada na relação desses trabalhadores com as políticas macrossociais e econômicas. Nesse sentido a aparente avaliação positiva desses programas se constitui quando:

As famílias inseridas no programa tiveram avanços significativos do ponto de vista do acesso e inserção. O resgate da auto-estima das mulheres com seu fortalecimento pessoal foi bastante expressivo. Os relatos apresentados mostram que as pessoas se apropriam de novas capacidades, sobretudo aquelas voltadas para o âmbito das relações interpessoais. Se a pobreza é, antes de tudo, ruptura de vínculos sociais e introjeção da subalternidade, este resgate, não só pessoal como social, vem dar um novo sentido à vida dessas pessoas, rompendo com a humilhação que a pobreza lhes impõe (Santos, 2006, p. 01).

Essa política social segue os preceitos contidos nas orientações do Banco Mundial (2009) que ao declarar em documento quais seriam as estratégias de parceria com o Brasil para os anos 2008-2011, prevê para o "desenvolvimento humano", o fortalecimento do capital humano e da força de trabalho, com um maior impacto dos serviços sociais e eficiência do gasto público. O Banco Mundial recomenda atuação em três áreas para o combate à pobreza:

I) Promover a oportunidade: Ampliar as oportunidades econômicas para os pobres, estimulando o crescimento geral, proporcionando-lhes mais bens (como 
terras e educação) e fazendo com que estes rendam mais, mediante uma combinação de ações públicas e privadas. II) Facilitar a participação: Tornar as instituições estatais mais responsáveis perante os pobres, fortalecendo a participação dos pobres nos processos políticos e decisões locais e eliminando as barreiras sociais que resultam das distinções de sexo, etnia, raça, religião e condição social. III) Aumentar a segurança: Reduzir a vulnerabilidade dos pobres a doenças, crises econômicas, perda de colheitas, desemprego, catástrofes naturais e violência, bem como ajudá-los a enfrentar choques adversos. Grande parte desse esforço consiste em assegurar a existência de redes de segurança para mitigar o impacto de calamidades pessoais e nacionais (p. 24).

A ideia de capital humano apoia-se no conceito de "capacidades", relacionado ao conjunto de bens que pode dominar para a expansão da sua liberdade em favor da responsabilidade individual (Stein, 2008). Ou seja, um "culto" ao individualismo e ao subjetivismo em detrimento da coletividade e das questões de classe, própria à ideologia liberal.

$\mathrm{Na}$ acepção liberal a ideia de justiça social está baseada em que todo o cidadão deve receber uma compensação para permitir que todas as pessoas disponham das mesmas possibilidades de escolha e das mesmas ocasiões no curso de suas vidas (Euzéby, 2004). No entanto, sabemos que sob o sistema capitalista isto é inviável, porque a desigualdade é inerente para a reprodução do sistema e que as possibilidades de escolhas estão determinadas por essa condição.

Na síntese das afirmações de Filgueiras e Gonçalves (2007) em suas críticas ao Programa Bolsa Família, podemos perceber como prevalece essa concepção hegemônica para justificar a pobreza e a desigualdade social:

- Transforma a pobreza em uma variável exógena aos mecanismos estruturais que reproduzem as desigualdades, bem como à estrutura e dinâmica do atual modelo de desenvolvimento capitalista, cuja explicação remete para o âmbito das famílias e indivíduos;

- Há uma desigual distribuição de "capital humano" entre os indivíduos e famílias, cujo fenômeno da pobreza decorre, fundamentalmente, do maior ou menor acesso à educação e saúde. Portanto, a pobreza é explicada pela ausência de "capital humano" nos indivíduos e famílias. Estabelece-se uma relação direta entre baixa escolaridade e pobreza, havendo uma única alternativa: políticas focalizadas de transferência de renda, 
condicionada a ações e iniciativas das famílias voltadas à educação dos filhos e cuidados com a saúde;

- A identificação das desigualdades se dá por meio das informações sobre os indivíduos e famílias sem relacioná-las com os rendimentos do capital ${ }^{21}$. Portanto, a distribuição pessoal/familiar da renda diz respeito às desigualdades existentes entre os trabalhadores que passam a ser classificados como: muito pobres, pobres, não pobres e ricos, segundo os níveis de renda;

- Os estudos sobre desigualdades no âmbito dos rendimentos do trabalho, à medida que restringem às disparidades salariais e de outros rendimentos do trabalho, excluem qualquer reforma que interfira na distribuição da propriedade fundiária, bem como a estrutura e o funcionamento do sistema financeiro;

- As políticas sociais consideradas mais eficientes e equânimes são aquelas que atingem os indivíduos mais necessitados, ou seja, cumprem com o objetivo da focalização, que são identificados por linhas de pobreza que subestimam as necessidades mínimas de sobrevivência de uma família.

A partir dessa análise, podemos perceber que tanto a explicação para a pobreza quanto as respostas para o seu enfrentamento contidas no PBF não ultrapassam os níveis mais imediatos das demandas sociais, excluindo suas relações estruturais com o modelo de produção e apropriação da riqueza no capitalismo. Ao permanecer no nível da aparência, não se alteram as bases fundantes da desigualdade social e da reprodução da pobreza. Do contrário, elas se perpetuam. Isso só faz afirmar que a cidadania assume o lugar de tensionamento que historicamente foi marcado pela luta de classes. Retira-se do cenário os conflitos entre capital e trabalho, para agora assumir a relação entre o Estado e os seus cidadãos.

As implicações ídeo-políticas desse processo só ampliam as dificuldades dos trabalhadores na tomada de consciência de classe e na luta por garantia e ampliação dos direitos, à medida que fragmenta suas condições, colocando-os uns contra os outros na luta pelos benefícios sociais, e transforma a pobreza em problema de gestão de recursos públicos apenas, sendo necessário focalizá-los para que se torne mais eficiente. 
Mantendo a superpopulação relativa viva e ideologicamente coerente com as propostas neoliberais, o Estado, representando os interesses do capital, não necessita impulsionar reformas de cunho estrutural e assim, ameniza as contradições entre as classes sociais.

\section{Desafios ao Serviço Social}

Diante das reflexões já realizadas, é necessário apontarmos, ainda que brevemente, para os desafios postos ao Serviço Social frente a atual conjuntura histórica. Desafios que sinalizam tanto para a formação profissional quanto para o exercício no cotidiano das instituições.

Primeiramente, é importante destacar que o assistente social, enquanto condição de trabalhador assalariado também sofre os impactos das medidas neoliberais, como na forma de contratação flexibilizada que muitas vezes ocorre por meio de contrato/projeto/assessoria tanto em instituições públicas quanto privadas. Além disso, vivencia a precarização do investimento nas políticas sociais, impactando na realidade cotidiana dos usuários e dos serviços e benefícios.

Por conta do aumento da pobreza, da institucionalização de novas questões contemporâneas e das formas de intervenção do Estado na questão social ocorre a ampliação dos espaços sócio-ocupacionais do Assistente Social. E nesse sentido, surgem novas "frentes" de trabalho para a profissão. Além dos tradicionais campos de atuação - a execução das políticas sociais - principalmente nas áreas da saúde, previdência e assistência social - emergem um conjunto de demandas para atuação junto à área sóciojurídica; aos programas e projetos que envolvem a questão urbana voltados à mobilidade e moradia popular; à área socioambiental; à esfera da educação pública a partir de políticas relacionadas à discriminação positiva que também abrangem políticas de acesso ou de inserção; à assessoria aos movimentos sociais que vem se ampliando, principalmente aos chamados "novos" movimentos sociais que defendem determinados segmentos sociais; e a consolidação da profissão enquanto área de conhecimento junto às ciências sociais (Mota, 2014).

Se historicamente, o assistente social era visto apenas para a execução imediata das políticas sociais, atualmente o Serviço Social ampliou as dimensões da prática profissional que fez alargar o universo de possibilidades da intervenção. Se por um lado, conta com a 
potencialidade para a inovação profissional, por outro, emergem um conjunto de requisições ligadas às outras áreas do conhecimento que precisam ser acionadas. O exemplo disto está na necessidade de apropriação sobre orçamento público, gestão de políticas sociais, elaboração de projetos, avaliação e monitoramento de projetos, programas e serviços, entre outros.

No entanto, devemos ficar atentos: se não forem apreendidas essas novas demandas institucionais na sua construção histórica e a partir do conjunto de mediações que a constituem, bem como se não nos apropriarmos de conhecimentos de outras áreas de forma crítica, tenderemos a responder a essas novas necessidades de forma imediata e pragmática. O que comprometerá análises mais totalizantes e por consequência, ações políticas sem o compromisso com a mudança social. Nesse sentido, a prática profissional voltada à fornecer respostas imediatas e emergentes às demandas institucionais pode trazer a centralidade do debate para a dimensão técnico-operativa da profissão relegando a um segundo plano o rigor teórico-metodológico e o compromisso ético-político.

Nesse sentido, queremos afirmar a necessidade do questionamento do pragmatismo no Serviço Social (Guerra, 2013). Uma vez que este possibilita a ampliação de teorias neoconservadoras, dificultando a qualificação do exercício profissional no que tange às reflexões num caráter crítico.

Na contramão da postura pragmática, reforçarmos a dimensão política da profissão e a necessidade de aprofundamento da teoria social crítica. Nesse sentido, é fundamental avançar cotidianamente na busca de identificar, reforçar e propor: iniciativas que evidenciem posturas anticapitalistas; processos de democratização das decisões; conquistas e possibilidades do exercício de direitos; mediações pedagógicas, éticas e formativas que contribuam para a formação da consciência crítica da população usuária (Mota, 2014).

Portanto, há a necessidade de reafirmar o rigor teórico-metodológico tanto na formação quando na fundamentação do exercício profissional para que possamos estabelecer uma unidade entre teoria e prática, sem cairmos no ecletismo teórico.

Torna-se fundamental, então, recorrermos às teorias que conectam as intervenções do Estado com a crise do capital que impactam na reestruturação de novas demandas aos Assistentes Sociais para avançarmos na constituição de respostas estratégicas que venham, de fato, a contribuir com a implementação e aprofundamento do projeto ético- 
político profissional voltado à constituição de estratégias técnico-operativas que realizem o efetivo enfrentamento da pobreza e da desigualdade.

Este artigo foi uma tentativa de incitar o debate crítico acerca do programa de transferência de renda no Brasil - o Programa Bolsa Família - inserido no atual contexto da política de assistência social - o SUAS - para que os profissionais que trabalham junto à execução e gestão dessas políticas possam se qualificar tanto no aprofundamento teórico quanto nas posturas políticas cotidianas. E assim poder construir análises críticas e respostas políticas consistentes e coerentes frente às novas demandas que são postas à profissão pelas instituições e usuários dos serviços.

\section{Referências Bibliográficas}

Anderson, P. (1995). Balanço do neoliberalismo. In: Sader, E. \& Gentile, P. (org.). Pósneoliberalismo - As políticas sociais e o Estado Democrático. Rio de Janeiro: Paz e Terra.

Banco Mundial (2009). Relatório sobre o desenvolvimento mundial 2000/2001: Luta contra a pobreza. Web site. Acessado em Janeiro 19, 2009 em http://www.bancomundial.org.br.

Behring, E. \& Boschetti, I. (2011). Política Social: Fundamentos e história. São Paulo: Cortez.

Carvalho, J. M. (2011). Cidadania no Brasil - um longo camino (14를 Ed). Rio de Janeiro: Civilização Brasileira.

Costanzi, R. \& Fagundes, F. (2010). Perfil dos beneficiários do Programa Bolsa Família. In: Castro, J. \& Modesto, L. Bolsa Família 2003-2010: avanços e desafios. Vol 01. Brasília: IPEA, 2010. Web site. Acesso em Março 29, 2015 em http://www.ipea.gov.br/portal/index.php?option=com_content\&view=article\&id=6604

Couto, B. (2006). O direito social e a assistência social na sociedade brasileira: uma equação possível? São Paulo: Cortez. 
Couto, B.; Yazbek, M. C; Silva, M. O. \& Raichelis, R. (org.) (2010). O Sistema Único de Assistência Social: uma realidade em movimento. São Paulo: Cortez.

Euzéby, A. (2004). Proteção social, pilar da justiça social. In: Sposati, A. (org.). Proteção social e cidadania - inclusão de idosos e pessoas com deficiência no Brasil, França e Portugal (11-32). São Paulo: Cortez.

Filgueiras, L. \& Gonçalves, R. (2007). A economia política do governo Lula. Rio de Janeiro: Contraponto.

Guerra, Y. (2013). Expressões do pragmatismo no Serviço Social: reflexões preliminares. Revista Katálysis, Florianópolis, v. 16, n. esp., p. 39-49.

lamamoto, M. \& Carvalho, R. (2005). Relações Sociais e Serviço Social no Brasil. (18ª Ed) São Paulo: Cortez; [Lima, Peru]: CELATS.

Ivo, A. (2008). Viver por um fio: pobreza e política social. São Paulo: Annablume; Salvador: $\mathrm{CRH} / \mathrm{UFBA}$.

Marx, K. (1998). O capital: crítica da economia política. v.1. e v. 2. 3 ed. Trad. Regis Barbosa e Flávio R. Kothe. São Paulo: Nova Cultural.

Mazzeo, A. (1997). Estado e Burguesia no Brasil: Origens da autocracia burguesa. (2ª Ed). São Paulo: Cortez.

Mota, A.E. (2014). Espaços ocupacionais e dimensões políticas da prática do Assistente Social. Revista Serviço Social e Sociedade, São Paulo, n. 120, p. 694-705. out./dez. 2014.

(2005). Cultura da crise e seguridade social: um estudo sobre as tendências da previdência e da assistência social brasileira nos anos 80 e 90. 3. ed. São Paulo: Cortez.

Rodrigues, M. T (2008). Eqüidade de gênero e transferência de renda: Reflexões a partir do Programa Bolsa Família. In: Boschetti, I.; Behring, E.; Santos, S.M. \& Mioto, R. (org.). Política social no capitalismo: tendências contemporâneas (220-241). São Paulo: Cortez. 
Santos, A. A. (2006) Avaliação do programa de transferência de renda de Londrina: Um olhar para além da renda. Serviço Social em Revista, v. 08, n.02, Londrina/PR, Universidade Estadual de Londrina.

Silva, M. O.; Yasbek, M. C. \& Giovanni, G. (2008) A política Social Brasileira no Século XXI : A prevalência dos programas de transferência de renda. (4⿳亠口冋. ed. rev. e atual). São Paulo: Cortez.

Stein, R.H (2008). Configuração recente dos programas de transferência de renda na América Latina: focalização e condicionalidade. In: Boschetti, I.; Behring, E.; Santos, S. M. \& Mioto, R. (org.) Política social no capitalismo: tendências contemporâneas (196-219). São Paulo: Cortez.

\section{Citacões}

${ }^{1}$ Conforme a Comissão Econômica para a América Latina e Caribe (CEPAL) o Brasil contava em 2005 com 36,4\% da população em situação de pobreza e 10,7\% em situação de indigência reduzindo para 18,0\% e 5,9\% em 2013. Informações obtidas através do documento “Panorama Social da América Latina" publicado em 2014. Disponível no site: http://cepal.co/wp-content/uploads/sites/8/2015/01/S1420729 es1.pdf. Acesso em 02/04/2015.

${ }^{2}$ A questão social não é senão as expressões do processo de formação e desenvolvimento da classe operária e de seu ingresso no cenário político da sociedade, exigindo seu reconhecimento como classe por parte do empresariado e do Estado. É a manifestação, no cotidiano da vida social, da contradição entre o proletariado e a burguesia, a qual passa a exigir outros tipos de intervenção, mais além da caridade e da repressão (IAMAMOTO, 2005, p. 77).

${ }^{3}$ Conforme Lei n.o 8.742, de 07 de dezembro de 1993. Afirmando que a assistência social tem por objetivos: I a proteção à família, à maternidade, à infância, à adolescência e à velhice; II - o amparo às crianças e adolescentes carentes; III - a promoção da integração ao mercado de trabalho; IV - a habilitação e reabilitação das pessoas portadoras de deficiência e a promoção de sua integração à vida comunitária; $V$ - a garantia de 01 (um) salário mínimo de benefício mensal à pessoa portadora de deficiência e ao idoso que comprovem não possuir meios de prover a própria manutenção ou de tê-la provida por sua família.

${ }^{4}$ Conforme Lei n. 9 8.080, de 19 de setembro de 1990, que tem entre os seus princípios a universalidade de acesso aos serviços de saúde em todos os níveis de assistência; a integralidade de assistência, entendida como conjunto articulado e contínuo das ações e serviços preventivos e curativos, individuais e coletivos, exigidos para cada caso em todos os níveis de complexidade do sistema.

${ }^{5}$ Para melhor análise acerca do surgimento e das primeiras experiências do neoliberalismo nos países centrais e periféricos ver Anderson (1995). 


\footnotetext{
${ }^{6}$ Conforme Lei n.․ 10.219, de 11 de abril de 2001.

${ }^{7}$ Conforme Medida Provisória n.o 2.206-1, de 06 de setembro de 2001.

${ }^{8}$ Conforme Decreto da Presidência da República n.ำ no 4.102, de 24 de janeiro de 2002.

${ }^{9}$ Conforme a Lei n.o 10.836, de 09/01/2004, integra o Plano Brasil Sem Miséria, que tem como foco de atuação os milhões de brasileiros com renda familiar per capita inferior a $\mathrm{R} \$ 77$ mensais.
}

${ }^{10}$ Para uma melhor compreensão do modo em como está constituída a atenção básica e especial no âmbito do SUAS consultar resolução n.o 145, de 15/10/2004 do Conselho Nacional de Assistência Social (Diário Oficial da União de 28/10/2004) que resolveu aprovar a Política Nacional da Assistência Social; e resolução também do referido conselho que aprovou em 15/07/2005 a Norma Operacional Básica/SUAS. Tais documentos podem ser encontrados no site: www.mds.gov.br.

11 Conforme dados oficiais disponíveis em http://www.mds.gov.br/bolsafamilia/beneficios. Acesso em 29/03/2015.

${ }^{12}$ Os benefícios variáveis acima descritos são limitados a 05 (cinco) por família

${ }^{13}$ Limitado a 02 (dois) benefícios por família.

${ }^{14}$ Conforme dados oficiais disponíveis em http://www.mds.gov.br/bolsafamilia/condicionalidades. Acesso em $29 / 03 / 2015$

${ }^{15}$ O Suas engloba também a oferta de Benefícios Assistenciais, prestados a públicos específicos de forma articulada aos serviços, contribuindo para a superação de situações de vulnerabilidade. Também gerencia a vinculação de entidades e organizações de assistência social ao Sistema, mantendo atualizado o Cadastro Nacional de Entidades e Organizações de Assistência Social e concedendo certificação a entidades beneficentes, quando é o caso. Conforme dados oficiais disponíveis em http://www.mds.gov.br/assistenciasocial/suas. Acesso em 29/03/2015

15 Conforme dados oficiais disponíveis em http://www.mds.gov.br/assistenciasocial/suas. Acesso em 29/03/2015.

16 Conforme dados oficiais disponíveis em http://www.mds.gov.br/assistenciasocial/suas. Acesso em $29 / 03 / 2015$.

${ }^{17}$ De acordo com a LOAS, as ações na área de assistência social são organizadas em sistema descentralizado e participativo. As ações das três esferas de governo na área de assistência social realizam-se de forma articulada, cabendo a coordenação e as normas gerais à esfera federal e a coordenação e execução dos programas, em suas respectivas esferas, aos Estados, ao Distrito Federal e aos Municípios.

18 Conforme dados oficiais disponíveis em http://bolsafamilia10anos.mds.gov.br/node/124. Acesso em $\underline{29 / 03 / 15}$. 
${ }^{19}$ Dados obtidos através do site: http://www.bbc.co.uk/portuguese/noticias/2014/09/140918 desigualdade ibge brasil_pnad_rb Acesso em 04/04/15.

${ }^{20}$ A média de benefício destinado às famílias é em torno de $\mathrm{R} \$ 152,00$ e o valor atual do salário mínimo é $\mathrm{R} \$$ 788,00, o que também é considerado baixo se levarmos em consideração a pesquisa do Departamento Intersindical de Estatísticas e Estudos Socioeconômicos (DIEESE) que fez um cálculo medindo o preço dos produtos da cesta básica definiu que o valor do salário mínimo deveria ser de $\mathrm{R} \$ 3.118,62$.

${ }^{21}$ A respeito desta discussão, Salvador (2009) destaca que: “diversos estudos revelam que a carga tributária brasileira aumentou muito nos últimos anos. De fato, já é mais alta que a de muitos países desenvolvidos. Mas, ao contrário desses países, o Brasil tira a maior parte de sua receita de tributos indiretos e cumulativos, que oneram mais o trabalhador e a classe média. Na composição da receita tributária, mais da metade da carga provém de tributos que incidem sobre bens e serviços, enquanto a tributação sobre a renda não ultrapassa $25 \%$ do total" (p. 15).

Haidée de Caez Pedroso Rodrigues é Professora Assistente da Escola de Serviço Social da Universidade Federal Fluminense (UFF) de Niterói/RJ. Doutoranda da Escola de Serviço Social da Universidade Federal do Rio de Janeiro, e Mestre pelo Programa de PósGraduação em Serviço Social da Universidade Federal de Pernambuco (2009), tendo seus estudos e experiências profissionais voltadas para as temáticas de trabalho, questão social e políticas sociais. Possui graduação em Serviço Social pela Pontifícia Universidade Católica do Rio Grande do Sul (2002) e especialização em Projetos Sociais e Culturais pela Universidade Federal do Rio Grande do Sul (2003). É vinculada ao Núcleo de estudos e pesquisas sobre Trabalho, política, movimentos sociais e Serviço Social.

haideerodrigues@yahoo.com.br 